\title{
Spatial distribution and associated factors of antenatal care utilization in Ethiopia in 2019: Spatial and multilevel analysis
}

Samuel Hailegebreal ( $\nabla$ samuastd@gmail.com )

Arba Minch University

Girma Gilano

Arba Minch University

Binyam Tariku Seboka

Dilla University

Mohammedjud Hassen Ahmed

Mettu University

Atsedu Endale Simegn

Wachemo University

Research Article

Keywords: Prevalence, ANC, utilization, EMDHS, Ethiopia

Posted Date: June 3rd, 2021

DOI: https://doi.org/10.21203/rs.3.rs-537337/v1

License: (9) This work is licensed under a Creative Commons Attribution 4.0 International License.

Read Full License 


\section{Spatial distribution and associated factors of antenatal care utilization in}

2 Ethiopia in 2019: Spatial and multilevel analysis

3 Samuel Hailegebreal $^{1 *}$, Girma Gilano ${ }^{1}$, Binyam Tariku Seboka ${ }^{2}$,Mohammedjud Hassen

$4 \quad$ Ahmed $^{3}$, Atsedu Endale Simegn ${ }^{4}$

5

$6 \quad$ Affiliation

$7 \quad{ }^{1}$ Arba Minch University, College of Medicine and Health Sciences, School of Public Health

8 Department of Health Informatics, Ethiopia

$9 \quad{ }^{2}$ Department of Health Informatics, College of Medicine and Health Sciences, Dilla University, 10 Ethiopia

$11{ }^{3}$ Department of Health Informatics, Institute of Public Health, Mettu University, Ethiopia

$12{ }^{4}$ Department of Anesthesia, Wachemo University, Ethiopia

14 Corresponding author

15 Samuel Hailegebreal

16 samuastd@gmail.com 


\section{Abstract}

22 Background: Antenatal care utilization key to reduces pregnant women death and preparing

23 women for birth. In Ethiopian antenatal care utilization was still not meet health sector

24 transformation plan. There was also regional variation of antenatal care services in the country.

25 Therefore, current study was aimed to explore spatial distribution and associated factors of 26 antenatal care utilization in Ethiopia based on the nationally representative EMDHS data.

27 Methods: Secondary data analysis was done on 2019 Ethiopian mini demographic and health

28 survey (EMDHS) data. ArcGIS 10.7 statistical software were used for spatial analysis. Bernoulli

29 model was fitted by applying Kulldorff methods using the StatsCan 9.6.1 software to analyze the

30 purely spatial clusters of ANC utilization. For associated factor mixed effect multilevel logistic

31 regression was fitted. Inter class correlation (ICC), Median odds ratio (MOR), proportional change

32 variance (PVC) and Deviance used for model comparison and fitness. Adjusted odds ratio (AOR)

33 with $95 \%$ confidence interval (CI) was used to declare significant factors of antenatal care

34 utilization.

35 Results: The prevalence of antenatal care utilization in Ethiopia was 75\% [95 CI: 73\%, 76\%] in

36 this study. The spatial distribution of antenatal car utilization was non-random across the country

37 with Global Moran's Index value of 0.032 , and significant P-value $(\mathrm{p}<0.05)$. For associated factor

38 secondary and higher education were 4.2 and 6 time greater than that of no formal education

39 women with AOR of 4.2(1.99-8.66) and $6(1.62-22)$ respectively. The odds of richest households

40 were 4.2 times AOR (1.08-2.3) and the odds of married, windowed, and divorced women were 6,

418 and 4.4 time more that of single women respectively in utilizing ANC. The odd of women

42 utilizing ANC was 4.2 times AOR (6.25-10.62). 
43 Conclusion: The spatial distribution of ANC utilization in Ethiopia is non-random. Maternal

44 education, marital status, wealth index, place of delivery, pregnancy status region and community

45 women education were significant predicter of antenatal care utilization in Ethiopia. Government

46 and non-governmental organization should scale up maternal health services to low-rate

47 area(hotspot) and poorest women.

48 Keywords: Prevalence, ANC, utilization, EMDHS, Ethiopia

49

50

51

52

53

54

55

56

57

58

59

60

61

62

63

64 


\section{Introduction}

66 According to the World Health Organization (WHO), Antenatal care (ANC) is a service delivered

67 by qualified professionals to pregnant women and adolescent girls for the best of women's and

68 babies health. The first visit is recommended within the 12 weeks of gestation and the next at 20,

$6926,30,34,36,38$, and 40 weeks of gestation(1). Risk identification; management and prevention

70 of pregnancy-related diseases; health education and health promotion are the activities women

71 served during the $\mathrm{ANC}(2)$. Of course, protecting women during pregnancy time remained the

72 single most important activity in maternal health for every country in the world (3). However, the

73 duty of maternal health care is not an easy task for developing countries where essential resources

74 are very limited which made the problem still predominant. Ethiopia shares the big burden of the

75 problem in the African continent. In many parts of the country, less than $50 \%$ of the pregnant

76 women followed $\mathrm{ANC}(4$, The coverage has been very well in the area with access, availability,

77 good educational status of the mother, and good wealth indices $(6,7)$. There are other factors that

78 determined ANC in the piece of literature. A study conducted in the Tigray region showed marital

79 status, education, the proximity of health facility to the village, and husband's occupation were all

80 affected the uptake of the $\operatorname{ANC}(7)$.

81 From the Ethiopian demographic health survey(EDHS) 2016, we learned: residence; husband

82 educational status; distance to the health institutions; community-level educational status;

83 community-level service utilization influenced optimal ANC; however, peak ANC was witnessed

84 in Addis Ababa, Tigray, Harari, and Dire Dawa regions, while low ANC utilization was seen in

85 Afar, Amhara, Oromia Benishangul, SNNP, and Somalia regions(8). Another analysis from the

86 same dataset revealed that Islamic religion, mother education, and distance from health

87 institutions, birth order, wealth index, rural residence, and high community media exposure were 
88 indeed deterring utilization. Spatial distribution was also not random. The Northeast Amhara, west

89 Benishangul Gumuz, Somali, Afar, north, and northeast SNNPR had poor utilization spots and

90 good but not optimal utilization in Tigray, Addis Ababa, and Dire Dawa regions(9). The country

91 has a health sector transformation plan (HSTP) of the increasing proportion of women having at

92 least 4 visits of Antenatal Care from $68 \%$ to $95 \%(10)$. According to the existing kinds of literature,

93 the plan is far from its achievement as there is no study ever presented with such information. The

94 ANC distribution in the country was: ANC 1-3 (45.71\%) and $\geq 4 \operatorname{ANCs}(54.29 \%)$ from EDHS

$952016(11) ; 62.8 \%$ overall ANC utilization from EDHS 2016(12); 29.3\% in the Northeast Ethiopia

96 in 2016(4); 54\% ANC in Tigray in 2013; 42.8\% in 2014 in Ambo Town (13); 77.4\% in Sidama

97 Zone in South Nation Nationalities people's region (SNNPR) in 2011(14); 72.6\% in Gedeo zone

98 in 2020(6); 78.5\% $\geq 4$ ANCs in Debre Berhan in 2019(15); 66.3\% of women not used ANC at first

99 trimester and 22.3\% had four and less ANC from EDHS 2011(16); urban women use 34\% more

100 ANC than rural women(17); the average ANC between 2000 and 2017(36.2\%)(18). This showed

101 exactly the position of the country in achieving the plan.

102 Although there is an improvement in utilization of ANC from 2011 to the current time, it is still

103 outlying from achieving the HSTP. Since there is no country representative study after EDHS

1042016 , the current study has enormous value in identifying spatial distribution, magnitude, and

105 associated factors for further planning and interventions at the country level.

\section{Methods}

107 Study design, setting, and period

108 We employed a cross-sectional data from Ethiopia Interim Demographic Health Survey (EMDHS)

109 2019. The 2019 EMDHS sample was stratified and selected in two stages. Each region was

110 stratified into urban and rural areas, yielding 21 sampling strata. Samples of EAs were selected 
111 independently in each stratum in two stages. In the first stage, a total of 305 EAs (93 in urban areas

112 and 212 in rural areas) were selected with probability proportional to EA size (based on the 2019

113 PHC frame) and with independent selection in each sampling stratum. In the second stage of

114 selection, a fixed number of 30 households per cluster were selected with an equal probability

115 systematic selection from the newly created household listing. Ethiopia is the second most

116 populous country in African continent situated at $\left(3 \mathrm{o}-14 \mathrm{oN}, 33 \mathrm{o}-48^{\circ} \mathrm{E}\right)$. EMDHS is the country

117 representative sample survey carried out between EDHSs follows all EDHS protocols mentioned

118 here. The country has nine regions and two city administrations which further categorized in to 119 contextual group as agrarian (Amhara, Benishangul-Gumuz, Gambela, Harari, Oromia, Southern

120 Nations, Nationalities, and People Region (SNNPR), and Tigray), pastoralists (Afar and Somali),

121 and city administrations (Addis Ababa and Dire-Dawa). We retrieved the data for this study from

122 the DHS website (www.dhsprogram.com) when downloading request permitted. The census

123 frame is a complete list of 149,093 EAs created for the 2019 PHC. An EA is a geographic area

124 covering an average of 131 households. The detailed sampling procedure has been presented in

125 the full EMDHS 2019 report(19).

\section{Study variables}

127 The outcome variable for this study is antenatal care utilization. In this study, antenatal care 128 utilization was defined as: Women who visited health facility at least once during their last 129 pregnancy were considered as antenatal care service utilizer, otherwise, not

130 Individual level variable: Age, education status, household wealth, literacy level, place of 131 delivery, birth order, parity, pregnancy status, age at first birth, religion, marital status,

132 Community level variable: variable: region, type of place of residence, community level 133 education, and community poverty level. 


\section{Data management and analysis}

135 Data was presented as descriptive statistics (weighted frequencies, mean, standard deviations, and 136 percentage or proportions and statistical (STATA 15, ArcGIS 10.7, and SaTscan 9.6.1) soft wares.

137 Disproportional sampling was corrected by weighting the data before applying analyses.

138 When the subjects in a study have a linear relationship with the dependent variable, traditional 139 regressions are the possible choice for analysis; however, since data from EMDHS are usually 140 hierarchical in nature, we planned to conducted multilevel analysis. To determine random effect,

141 Intra-community Correlation (ICC) was estimated as ICC $=\frac{\sigma_{a}^{2}}{\sigma^{2} a^{+} \sigma^{2}{ }_{b}}$; where, $\sigma^{2}{ }_{a}$ is the community 142 level variance and $\sigma_{b}^{2}$ indicates individual level variance. The individual variance $\left(\sigma_{b}^{2}\right)$ equal 143 to $\pi^{2} / 3$ that is the fixed value

144 Model comparison was done using Likelihood Ratio (LR) test and goodness of fit was assessed 145 using deviance (-2LL)). Median Odds Ratio (MOR) was estimated as $\mathrm{MOR}=\mathrm{MOR}=e^{0.95^{*}} \sqrt{V a_{-}}$, 146 where, $V a_{-} 1$ is the variance in the empty model and Proportional Change in Variance (PCV) was 147 estimated as $\mathrm{PVC}=\frac{V a_{\_} 1-V a_{\_} \_}{V a_{-} 1}$, where, $V a_{-} 1$ is variance of the empty model and $V a_{\_} 2$ is 148 neighborhood variance in the subsequent model).

\section{Statistical analyses}

150 We applied multilevel binary logistic regression for both individual and community-level model 151 building. The first model contained only outcome variable to learn nature of variation and the next 152 analysis choice; the second model included fixed effect variables; the third model included 153 community-level (random effect) variables and the remaining model contained mixed effect. The $154 \mathrm{p}$-value $<0.25$ was used to include variable in model and $\mathrm{p}$-value $<0.05$ was used to declare 155 association. With AOR and $95 \% \mathrm{CI}$ also used to describe the results.

\section{Spatial analysis}


157 We cleaned and dropped data with zero Latitudes/longitude and then applied spatial analyses using 158 ArcGIS 10.7 to appraise whether the pattern of data was clustered, dispersed, or random 159 distributed. SaTScan V.9.6 software detected the presence of local cluster. We used a circular 160 window that moves systematically throughout the study area to ascertain a significant clustering 161 of ANC utilization.

\section{Spatial autocorrelation analysis}

163 The spatial autocorrelation (Global Moran's I) was used to know if ANC utilization is dispersed, 164 clustered or random in the country. Moran's, I output varies between $(-1$ to +1$)$. Values close to $165-1$ indicated ANC utilization is dispersed whereas; value close to +1 is for clustered distribution.

\section{Spatial interpolation}

167 Spatial interpolation technique was applied to predict the unsampled value from sampled 168 measurement. Ordinary Kriging and empirical Bayesian Kriging methods were used to incorporate spatial autocorrelation and statistically optimize the weight. Ordinary Kriging spatial interpolation method was used for predictions of ANC utilization in unobserved areas of the country.

\section{Ethical consideration}

172 Since the study was a secondary data analysis of publicly available survey data from the

173 MEASURE DHS program, ethical approval and participant consent were not necessary for this 174 particular study. We requested DHS Program and permission was granted to download and use 175 the data for this study from http://www.dhsprogram.com. During data analyses we kept everything 176 confidential and no households or individual's information were identified. The EMDHS data 177 collection obtained permission from Ethiopian Health Nutrition and Research Institute (EHNRI)

178 Review Board and the National Research Ethics Review Committee (NRERC) at the Ministry of 
179 Science and Technology. Verbal informed consent for participation was collected after clearing 180 the purpose of the study.

\section{Result}

\section{Socio- demographic characteristics of study population}

183 We analyzed a total of 3,340 data of 15-49 age women from EMDHS 2019. Of these, 1259 (37.7\%)

184 were from Oromia region and $9(0.28 \%)$ were from Harari region. Majority (37.6\%) of the 185 respondents were orthodox Christian followers. Regarding the age, 1895(57\%) of them were 186 within age range of 15-29 years. Nearly, half (48\%) of respondent were not educated. Majority of 187 the respondents (73\%) were rural residents. Nearly, all participants $(3178(95.16 \%))$ were married 188 and greater than half $(62.32 \%)$ of the women were illiterate (Table.1).

190 The overall prevalence of antenatal care utilization in Ethiopia was 75\% [95 CI: 73\%, 76\%], which 191 was significantly varied across regions ranging from $30.1 \%$ in the Somali to $97.8 \%$ in Addis Ababa 192 (Fig.1).

\section{Spatial autocorrelation analysis}

194 The global spatial autocorrelation analysis showed that the spatial distribution of antenatal car 195 utilization was non-random across the country with Global Moran's Index value of 0.032, and 196 significant $\mathrm{P}-\mathrm{value}(\mathrm{p}<0.05)$ (Fig.2). In this finding, areas with a higher prevalence of antenatal 197 care utilization were identified in Addis Ababa, and Tigray regions. In contrast, areas with a lower 198 prevalence of antenatal care utilization were detected in part of SNNRP, Afar, and Somali, regions 199 (Fig.3) 
Based on EMDHS 2019 sampled data, ordinary kriging spatial interpolation predict the highest

202

203 204 205 206 207 208 209 prevalence of antenatal care utilization rates were in Addis Ababa, Dire Dawa, part of Somali, Gambella, and Harari region. In contrast, relatively low ANC utilization areas were predicted in Tigray, Afar, Amhara and some part of Oromia (Fig.4)

\section{Spatial scan statistics analysis}

In EMDHS 2019 total of 152 primary clusters were identified in spatial sat scan analysis detected in Addis Ababa, Amhara, and Tigray region (11.267438 N, 35.292874 E) / 510.34 km radius $(\mathrm{LLR}=60.56$ and $\mathrm{P}<0.001)($ Fig.5)

\section{Factors associated with ANC utilization}

\section{The random effect analysis result}

In the null model, $49.9 \%$ (ICC) directed that the total variability for antenatal care utilization was due to changes between clusters and the remained were attributable to within cluster. Additionally, the MOR of 4.6 in the null model showed the variation in antenatal care utilization between clusters. Finally, PCV of the mixed model showed $87 \%$ of the variability in antenatal care utilization was explained by the full model. The best fitted model was compared by deviance and the best fitted was model 3, with the lowest deviance (Table.2).

\section{The fixed effect analysis result}

In the multilevel logistic regression analysis, individual-level factors (maternal education, wealth index, marital status, place of delivery and pregnancy status), community-level facto (region and community women education) evidence of association with ANC utilization (Table.3).

The odds of utilizing ANC among women with secondary and higher education were 4.2 and 6 time greater than that of no formal education women with AOR of 4.2(1.99-8.66) and $6(1.62-22)$ respectively. The odds of richest households were 4.2 times greater than that of poorest households 
224 with AOR of 4.2(1.08-2.3) and the odds of married, windowed, and divorced women were 6, 8 225 and 4.4 time more that of singe women respectively in utilizing ANC.

226 The odd of women utilizing ANC was 4.2 times greater among women practiced institutional 227 delivery than that of home delivery with AOR of 4.2(6.25-10.62). The odds of women utilizing 228 ANC was decreased by $21 \%$ among pregnant the than that of not/unsure of pregnancy AOR 229 0.79(0.51-0.95). Regarding regions, women living in Afar $(\mathrm{AOR}=0.17 ; 95 \% \mathrm{CI}, 0.07-0.40)$,

230 Oromia $(\mathrm{AOR}=0.17 ; 95 \% \mathrm{CI}, 0.08-0.38)$, Somali $(\mathrm{AOR}=0.035 ; 95 \% \mathrm{CI}, 0.014-0.08)$, 231 Benishangul $(\mathrm{AOR}=0.29 ; 95 \% \quad \mathrm{CI}, 0.13-0.64) \quad(\mathrm{AOR}=0.18 ; 95 \% \mathrm{CI}, 0.08-0.38)$, Gambella $232(\mathrm{AOR}=0.19 ; 95 \% \mathrm{CI} 0.08-0.42)$, Harari $(\mathrm{AOR}=0.14 ; 95 \% \mathrm{CI}, 0.057-0.35)$, and $(\mathrm{AOR}=0.19 ; 95 \%$ 233 CI 0.075-0.47) had lower odds of ANC utilization compared to Tigray region. Women living in 234 high community's educational status had more ANC utilization those in low with AOR of $235 \quad 1.5(1.03-2.14)$.

\section{Discussion}

237 The current study was aimed to explore spatial distribution and associated factors of antenatal care 238 utilization in Ethiopia based on the nationally representative EMDHS data. We analyzed 3,340 239 data of women ages 15-49 from EMDHS 2019 and the average ANC of the country was 75\%; 240 however, the current ANC is less than the target of Ethiopian HSTP which is 95\%(10); however, 241 the finding was greater than the ANC utilization of $62.58 \%$ of EDHS $2016(15)$. From this, we 242 saw that there was an increase by $12.2 \%$ in ANC utilization.

243 Despite the increase in utilization of ANC in Ethiopia, the finding is less than the Ayder-Mekelle 244 (88.9\%), South African (78.1\%), and Zimbabwe (76.2\%) ANC utilization which showed there is 245 still a big room for improvement(18,21,22). As evidence by $30.1 \%$ utilization in the Somali and 
97.8\% in Addis, disparities among the regions are very significant. At country level, it might

247 stipulation of considering socio-demographic factors which are extremely very important to deal with in resource limited countries. Almost every studies conducted country level samples support the existence of such disparities and that is the sign for the need of region specific interventions $(8,9,22,23)$. For instance, the current analysis showed $48 \%, 73 \%$, and $62.32 \%$ of respondents were not learned, living in rural residences, and illiterates respectively and this is also supported by a plenty of evidences in literature(11,23-26). The reason might be all efforts made to get women learned, economically empowered, making easy access to service in rural residences, and reducing illiteracy were not good enough as study after study reported similar findings.

255 The spatial analysis revealed that the antenatal care utilization across the country was varied. In this finding, Addis Ababa, and Tigray regions were identified as high prevalence of antenatal care

257 utilization. In contrast, areas with a lower prevalence of antenatal care utilization were detected in part of SNNRP, Afar, and Somali, regions. This finding supported previous study in Ethiopia(25), Indonesia(26). Might be the disparity in the unavailability of maternal health services, and the inaccessibility of set-up such as road and transportation could be the possible reasons. So, this antenatal care utilization in this significant low-rate area of the country.

In the multilevel logistic regression analysis; maternal education, wealth index, marital status, place of delivery and pregnancy status, region and community women education were significantly 265 associated with antenatal care utilization. Women level educational statuses of secondary and 266 above were showed correlation with ANC. There is large evidence supporting the current 267 finding(27). The reason might be due increase in awareness in because educational status which 268 their increased service utilization and might deserve further improvement. Wealth status also 
269 affected ANC and evidenced in other studies very well(12). This might also be the influence of 270 access that can be dwindled by the cost of transportations and others that were the global problems

271 of developing problems. Married, widowed, and divorced women had all conveyed history of ANC

272 in their last pregnancies. Other evidences also showed that having any type of marital status was 273 related to ANC(17)(11). Of course, this worthy nothing as no one would expect more ANC from 274 non-formally married women. The positively correlation of institutional delivery, might be due to 275 the increased contact between health professionals and women service takers and that is why health 276 provider should promote service utilization every time they get access to women. Other studies 277 portraits the same finding in many parts of the country(11,28). Women utilizing ANC was 278 decreased among pregnant the than that of not/unsure of pregnancy. This finding inline other 279 study(29). The possible explanation might be women initiated antenatal care late because they 280 wanted to delay making the pregnancy public, because of fear of perceived "enemies" who could 281 harm their pregnancies.

282 Among the community-level variables, it was revealed that the odds of antenatal care utilization 283 residing in the Afar, Oromia, SNNPR, Benishangul, Gambella, Harari and Dire dawa region were 284 nearly similar as compared to Tigray. Whereas, Somali is found to be the lower in this analysis. 285 This finding supported by previous EDHS survey(30,31). This could be due to an imbalance of 286 demand and supply like poor infrastructure and poor-quality in-service delivery. In places where 287 community level education was very good, ANC utilization was found very well. The finding is 288 consistent with the 2016 EDHS finding. This might be due the linear relationship between ANC 289 and community level education(8). 
291 Even though the current study has strong interests in itself, national representatives give strong

292 evidence. It has also some limitations that need consideration while applying the findings.

293 Disproportion of sampling, third party data, inability to for casual relationship, and health

294 institution factors not incorporated were some of the limitations. Eased disproportion of sampling

295 by weighting, obtained complete permission to use data, and dropping records that don't fulfill

296 study definition were some of the attempt solutions.

\section{Conclusion}

298 In Ethiopia ANC utilization was nor meet the HSTP plan. The spatial distribution of ANC 299 utilization in Ethiopia is non-random. The higher prevalence of antenatal care utilization was found 300 in Addis Ababa, Tigray. Whereas, low proportion of ANC utilization found in Somali, Afar. 301 Maternal education, marital status, wealth index, place of delivery, pregnancy status region and 302 community women education were significant predicter of antenatal care utilization in Ethiopia. 303 Government and non-governmental organization should scale up maternal health services to low304 rate area(hotspot) and poorest women.

\section{Ethics approval and consent to participate}

307 We were registered, and requested data for analysis from DHS on-line archive. We received an 308 approval to download the dataset( http://www.measuredhsprogram.com). The geographic 309 coordinate data were obtained by explaining the purpose of using GPS data, and we receive 310 approval from the Measure DHS program. 


\section{Consent for publication}

313 Not applicable.

$314 \quad$ Availability of data and materials

315 The data in which the authors used to produce this manuscript are available upon reasonable 316 request

317 Competing interests

318 The authors declare that they have no competing interests.

$319 \quad$ Funding

320 No-funding

321 Authors' contributions

322 Proposal preparation, acquisition of data, analysis, and interpretation of data was done by SH, GG

$323 \mathrm{BT}, \mathrm{MJH}$, and AE instruct the study design data cleaning and analysis. SH drafted the manuscript 324 and all authors have a substantial contribution in revising and finalizing the manuscript. All authors 325 read and approved the final manuscript.

\section{Acknowledgements}

327 We would like to express our deepest thankfulness to Measure DHS, for providing the data for the 328 study.

329 Authors' information

330 Arba Minch University, College of Medicine and Health Sciences, School of Public Health 331 Department of Health Informatics, Ethiopia 
332 Samuel Hailegebreal and Girma Gilano

333 Department of Health Informatics, College of Medicine and Health Sciences, Dilla University,

334 Ethiopia

335 Binyam Tariku Seboka

336 Department of Health Informatics, Institute of Public Health, Mettu University, Ethiopia

337 Mohammedjud Hassen Ahmed

338 Department of Anesthesia, Wachemo University, Ethiopia

339 Atsedu Endale Simegn

340

341

342

343

344

345

346

347

348

349

350

351

352

353 


\section{References}

1. WHO. New guidelines on antenatal care for a positive pregnancy experience. Available from: https://www.who.int/news/item/07-11-2016-new-guidelines-on-antenatal-care-fora-positive-pregnancy-experience.

2. WHO recommendations on antenatal care for a positive pregnancy experience. 2005.https://apps.who.int/iris/bitstream/handle/10665/250796/9789241549912eng.pdf?sequence $=1$.

3. Alkema L, Chou D, Hogan D, Zhang S, Moller AB, Gemmill A, et al. Global, regional, and national levels and trends in maternal mortality between 1990 and 2015, with scenario-based projections to 2030: A systematic analysis by the un Maternal Mortality Estimation Inter-Agency Group. Lancet. 2016;387(10017):462-74.

4. Tadesse E. Antenatal care service utilization of pregnant women attending antenatal care in public hospitals during the COVID-19 pandemic period. Int J Womens Health. 2020;12:1181-8.

5. Woyessa $\mathrm{AH}$, Ahmed TH. Assessment of focused antenatal care utilization and associated factors in Western Oromia, Nekemte, Ethiopia. BMC Res Notes [Internet]. 2019;12(1):17. Available from: https://doi.org/10.1186/s13104-019-4311-3

6. Abeje A, Kassa ZY, Berhanu Z. UTILIZATION OF ANTENATAL CARE AND ASSOCIATED FACTORS IN GEDEO UTILIZATION OF ANTENATAL CARE AND ASSOCIATED FACTORS IN GEDEO ZONE, SOUTHERN ETHIOPIA. 2021;(February).

7. Tsegay Y, Gebrehiwot T, Goicolea I, Edin K, Lemma H, Sebastian MS. Determinants of antenatal and delivery care utilization in Tigray region, Ethiopia: A cross-sectional study. Int J Equity Health. 2013;12(1):1-10.

8. Tessema ZT, Animut Y. Spatial distribution and determinants of an optimal ANC visit among pregnant women in Ethiopia: Further analysis of 2016 Ethiopia demographic health survey. BMC Pregnancy Childbirth. 2020;20(1):1-13.

9. Tusa BS, Weldesenbet AB, Kebede SA. Spatial distribution and associated factors of underweight in Ethiopia: An analysis of Ethiopian demographic and health survey, 2016. PLoS One. 2020;15(12 December).

10. Federal Democratic Republic of Ethiopia Ministry of Health. Ethiopian Health Sector Transformation Plan.2015/16 - 2019/20. Fed Democr Repub Ethiop Minist Heal. 2015;20(May):50.

11. Muluneh AG, Animut Y, Ayele TA. Spatial clustering and determinants of home birth after at least one antenatal care visit in Ethiopia: Ethiopian demographic and health survey 2016 perspective. BMC Pregnancy Childbirth. 2020;20(1):1-13.

12. Tsegaye B, Ayalew M. Prevalence and factors associated with antenatal care utilization in Ethiopia: An evidence from demographic health survey 2016. BMC Pregnancy Childbirth. 
2020;20(1):1-9.

13. Meseret ETB. Determinants of Antenatal Care Utilization in Ambo Town, Central Ethiopia : Community Based Cross Sectional Study. 2017;36:1-8.

14. Regassa N. Antenatal and postnatal care service utilization in Southern Ethiopia: A population-based study. Afr Health Sci. 2011;11(3):390-7.

15. Tizazu MA, Asefa EY, Muluneh MA, Haile AB. Utilizing a minimum of four antenatal care visits and associated factors in debre berhan town, North Shewa, Amhara, Ethiopia, 2020. Risk Manag Healthc Policy. 2020;13:2783-91.

16. Yaya S, Bishwajit G, Ekholuenetale M, Shah V, Kadio B, Udenigwe O. Timing and adequate attendance of antenatal care visits among women in Ethiopia. PLoS One. 2017;12(9):1-16.

17. Zegeye EA, Mbonigaba J, Dimbuene ZT. Factors associated with the utilization of antenatal care and prevention of mother-to-child HIV transmission services in Ethiopia: Applying a count regression model. BMC Womens Health. 2018;18(1):1-11.

18. Adedokun ST, Yaya S. Correlates of antenatal care utilization among women of reproductive age in sub-Saharan Africa: evidence from multinomial analysis of demographic and health surveys (2010-2018) from 31 countries. Arch Public Heal. 2020;78(1):1-10.

19. Ethiopian Public Health Institute (EPHI) [Ethiopia] and ICF. 2021. Ethiopia Mini Demographic and Health Survey 2019: Final Report. Rockville, Maryland, USA: EPHI and ICF. Vailable from: https://dhsprogram.com/pubs/pdf/FR363/FR363.pdf.

20. Gayawan E, Omolofe OT. Analyzing Spatial Distribution of Antenatal Care Utilization in West Africa Using a Geo-additive Zero-Inflated Count Model. Spat Demogr. 2016;4(3):245-62.

21. Berhe KK, Welearegay HG, Abera GB, Hailemariam, BKahsay ABK. Assessment of Antenatal Care Utilization and its Associated Factors Among 15 to 49 Years of Age Women in Ayder Kebelle, Mekelle City 2012 / 2013 ; A Cross Sectional Study. Am J Adv Drug Deliv. 2014;1-14.

22. Tessema ZT, Tiruneh SA. Spatio-temporal distribution and associated factors of home delivery in Ethiopia. Further multilevel and spatial analysis of Ethiopian demographic and health surveys 2005-2016. BMC Pregnancy Childbirth. 2020;20(1):1-16.

23. Yeneneh A, Alemu K, Dadi AF, Alamirrew A. Spatial distribution of antenatal care utilization and associated factors in Ethiopia : evidence from Ethiopian demographic health surveys. 2018;1-12.

24. Defar A, Okwaraji YB, Tigabu Z, Persson LÅ, Alemu K. Geographic differences in maternal and child health care utilization in four Ethiopian regions; A cross-sectional study. Int J Equity Health. 2019;18(1):1-11. 
429 25. Yeneneh A, Alemu K, Dadi AF, Alamirrew A. Spatial distribution of antenatal care utilization and associated factors in Ethiopia: evidence from Ethiopian demographic health surveys. BMC Pregnancy Childbirth [Internet]. 2018;18(1):242. Available from: https://doi.org/10.1186/s12884-018-1874-2

433

26. Tripathi V, Singh R. Regional differences in usage of antenatal care and safe delivery services in Indonesia: findings from a nationally representative survey. BMJ Open [Internet]. 2017 Feb 1;7(2):e013408. Available from: http://bmjopen.bmj.com/content/7/2/e013408.abstract

437 27. Tiruaynet K, Muchie KF. Determinants of utilization of antenatal care services in Benishangul Gumuz Region, Western Ethiopia: A study based on demographic and health survey. BMC Pregnancy Childbirth. 2019;19(1):1-5.

28. Ali SA, Dero AA, Ali SA, Ali GB. Factors Affecting the Utilization of Antenatal Care among Pregnant Women in Moba Lga of Ekiti State, Nigeria. Int J Tradit Complement Med. 2016;2(2):41-5.

29. Warri D, George A. Perceptions of pregnant women of reasons for late initiation of antenatal care: A qualitative interview study. BMC Pregnancy Childbirth. 2020;20(1):112.

446 30. ECSA. Ethiopian Demographic Health Survey 2016. 2016. 161 p.

447 31. Central Statistical Agency, ORC Macro. Ethiopia Demographic and Health Survey 2005.

448 Heal San Fr [Internet]. 2006;(September):[446]. Available from: http://www.measuredhs.com/pubs/pdf/FR179/FR179[23June2011].pdf 


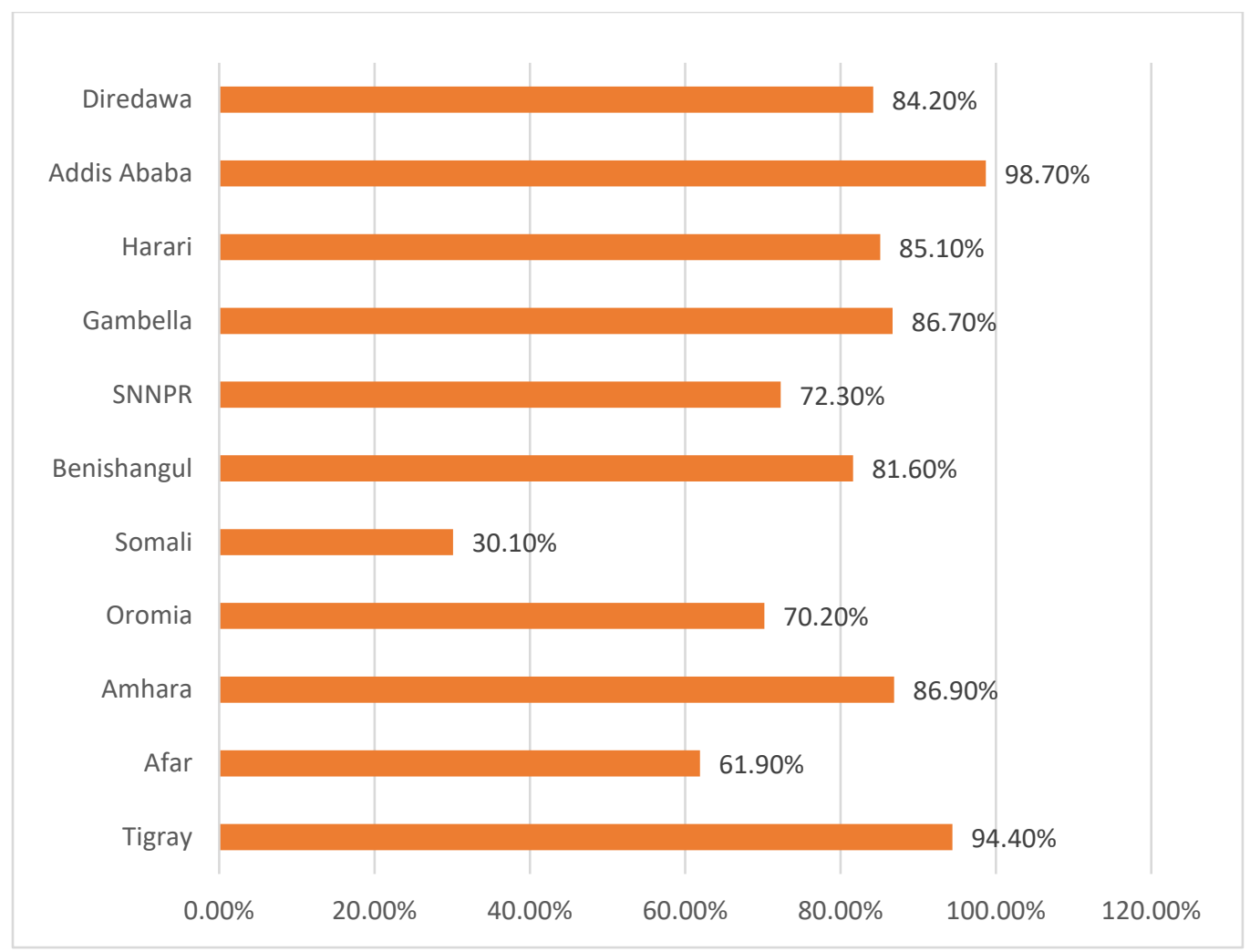

Fig 1. Regional prevalence of antenatal care utilization in Ethiopia, 2019 


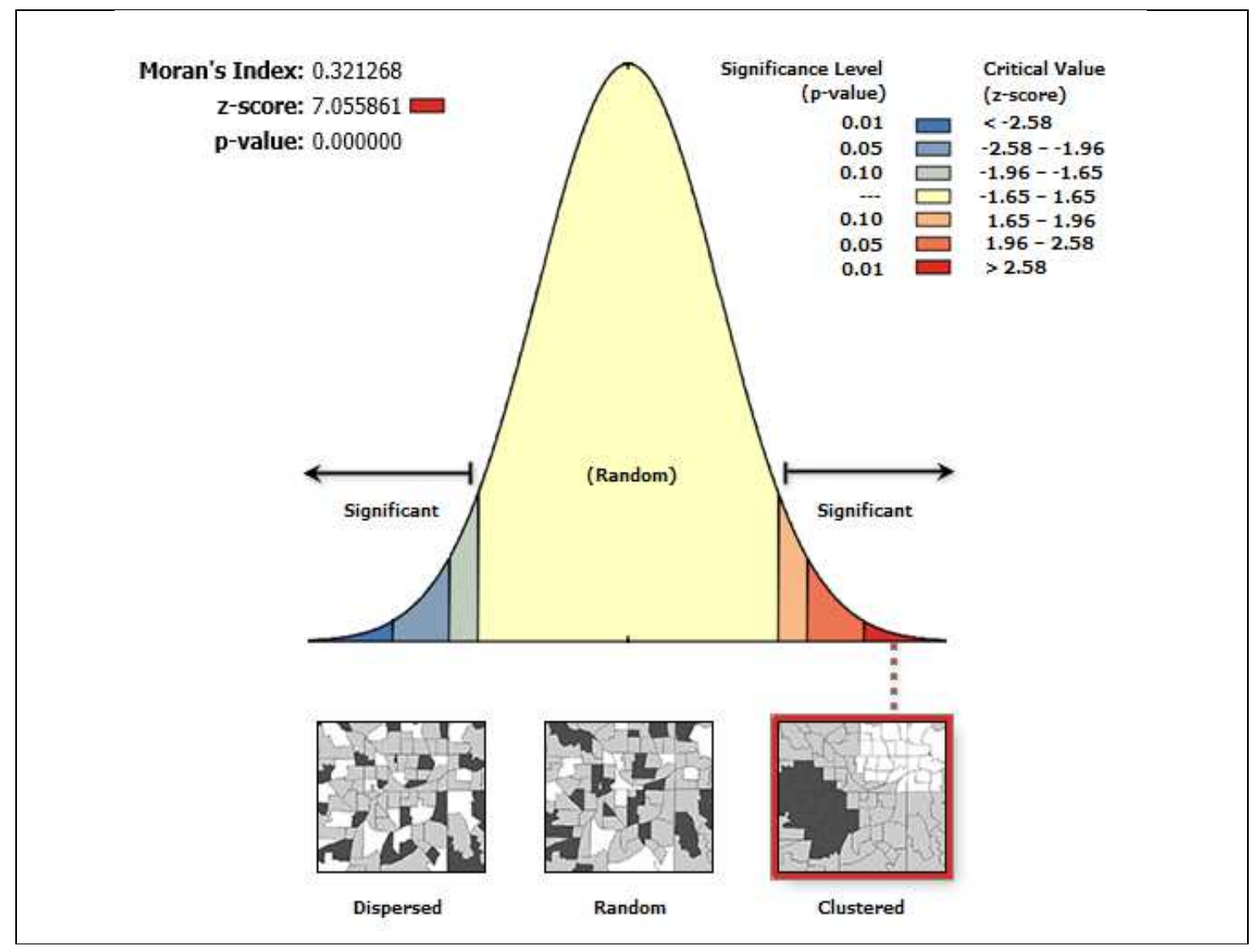

Fig.2 Spatial autocorrelation of ANC utilization in Ethiopia; 2019 


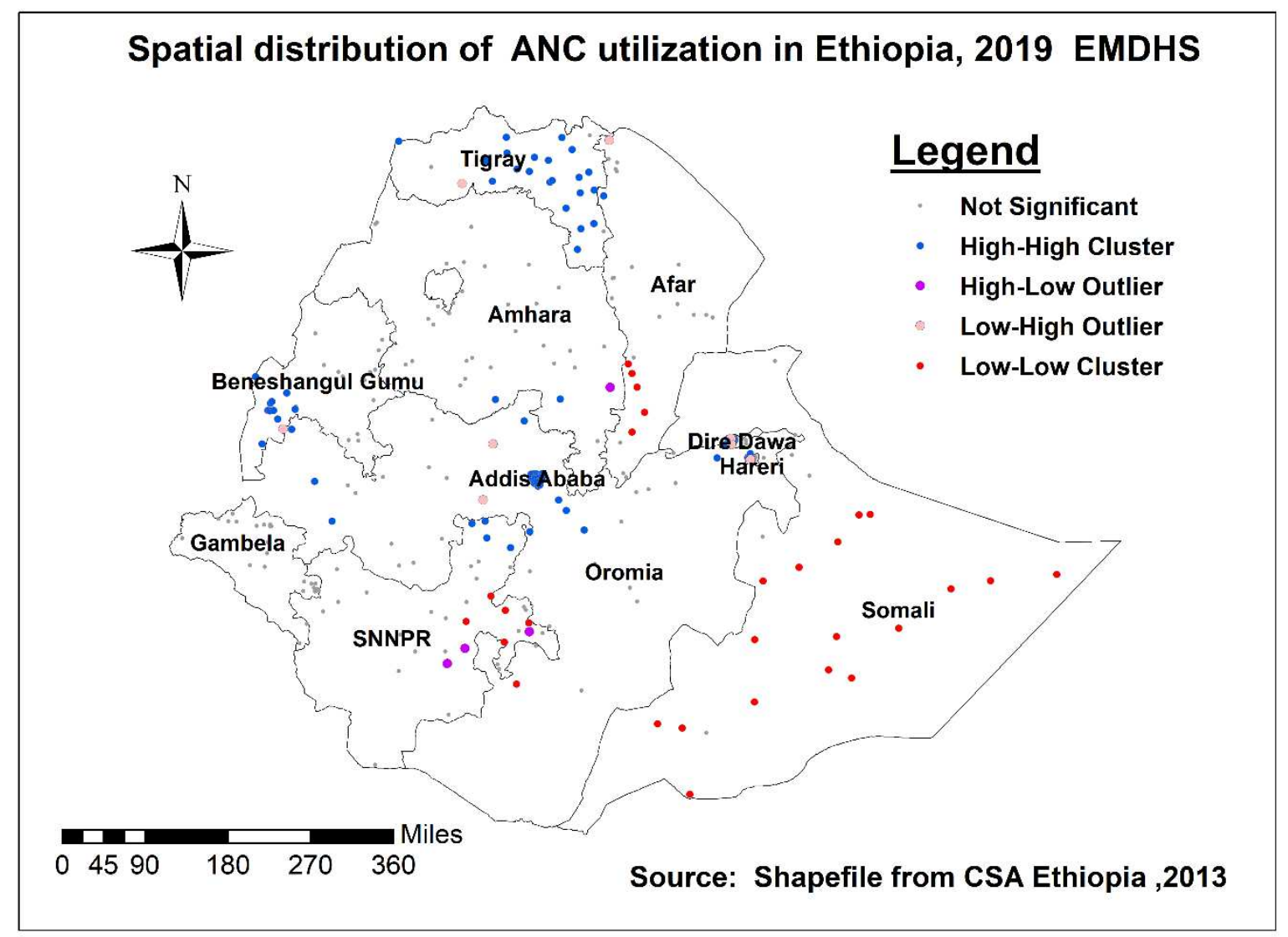

Fig.3 Spatial distribution of ANC utilization in Ethiopia, 2019 


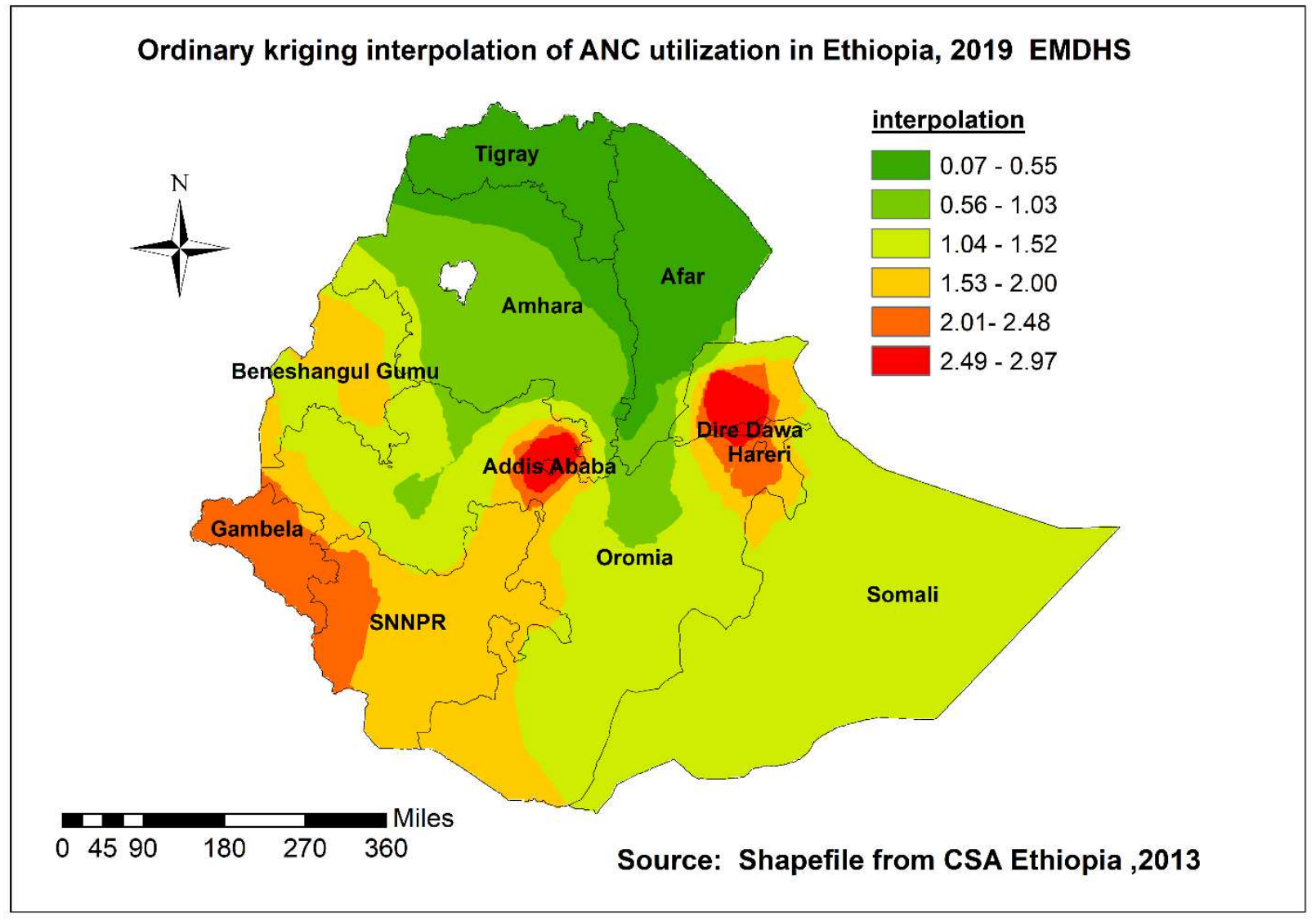

Fig.4 Ordinary kriging spatial interpolation of ANC utilization in Ethiopia ,2019 


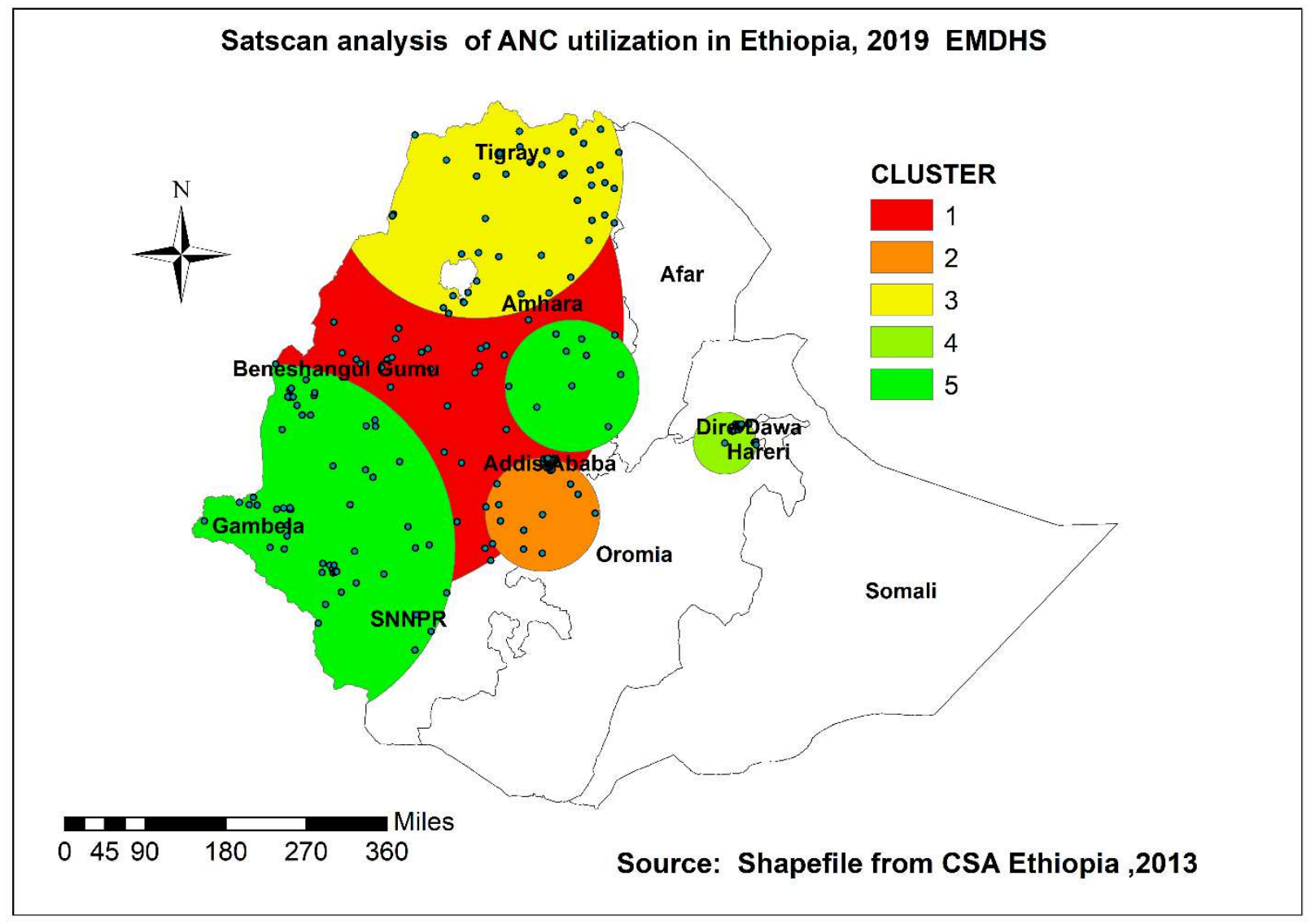

Fig.5 StatsCan analysis of ANC utilization in Ethiopia ,2019 
Table 1. Socio- demographic characteristics of study population (Weighted, $N=3,340$ )

\begin{tabular}{|c|c|c|}
\hline & Weighted frequency & Weighted (\%) \\
\hline \multicolumn{3}{|l|}{ Region } \\
\hline Tigray & 269 & 8 \\
\hline Afar & 42 & 1.3 \\
\hline Amhara & 716 & 21.5 \\
\hline Oromia & 1259 & 37.7 \\
\hline Somali & 196 & 5.9 \\
\hline Benishangul & 38 & 1.13 \\
\hline SNNPR & 657 & 19.52 \\
\hline Gambella & 15 & 0.5 \\
\hline Harari & 9 & 0.28 \\
\hline Addis Ababa & 120 & 3.6 \\
\hline Diredawa & 19 & 0.57 \\
\hline \multicolumn{3}{|l|}{ Residence } \\
\hline Rural & 2436 & 73 \\
\hline Urban & 904 & 27 \\
\hline \multicolumn{3}{|l|}{ Age } \\
\hline $15-29$ & 1895 & 57 \\
\hline $30-39$ & 1147 & 34 \\
\hline $40-49$ & 298 & 9 \\
\hline \multicolumn{3}{|l|}{ Religion } \\
\hline Orthodox & 1254 & 37.6 \\
\hline Muslim & 1158 & 34.7 \\
\hline Protestant & 884 & 26.5 \\
\hline Others & 44 & 1.3 \\
\hline \multicolumn{3}{|l|}{ Marital status } \\
\hline Single & 21 & 0.62 \\
\hline Married & 3178 & 95.16 \\
\hline Widowed & 34 & 1.02 \\
\hline
\end{tabular}




\begin{tabular}{|c|c|c|}
\hline Divorced & 107 & 3.2 \\
\hline \multicolumn{3}{|l|}{$\begin{array}{l}\text { Educational } \\
\text { status }\end{array}$} \\
\hline No-education & 1624 & 48.64 \\
\hline Primary & 1250 & 37.42 \\
\hline Secondary & 316 & 9.46 \\
\hline Higher & 150 & 4.48 \\
\hline \multicolumn{3}{|l|}{ Wealth status } \\
\hline Poor & 1387 & 41.52 \\
\hline Middle & 633 & 18.94 \\
\hline Rich & 1320 & 39.54 \\
\hline \multicolumn{3}{|l|}{ Literacy level } \\
\hline Illiterate & 2082 & 62.32 \\
\hline Literate & 1258 & 37.68 \\
\hline
\end{tabular}

Table.2 Random effect analysis result

\begin{tabular}{|l|l|l|l|l|}
\hline Parameter & Null model & Model I & Model II & Model II \\
\hline Community-level variance & 3.23 & 0.77 & 0.89 & 0.41 \\
\hline Loglikelihood & -1595.5 & -1297.8 & -1472 & -1251 \\
\hline Deviance & 3191 & 2595.6 & 2944 & 2502 \\
\hline MOR & 4.6 & 2.3 & 2.4 & 1.7 \\
\hline PVC & Ref & $76 \%$ & $72 \%$ & $87 \%$ \\
\hline ICC & 0.49 & 0.19 & 0.21 & 0.11 \\
\hline
\end{tabular}


Table.3 individual-level and community-level factors associated with antenatal care use in Ethiopia, EMDHS 2019

\begin{tabular}{|c|c|c|c|c|}
\hline Variables & Model 0 & Model 1 & Model 2 & Model 3 \\
\hline \multicolumn{5}{|c|}{ Individual- level variables } \\
\hline \multicolumn{5}{|l|}{ Respondent age } \\
\hline $15-29$ & - & Ref & - & Ref \\
\hline $30-39$ & - & $1.4[1.05-1.97] *$ & - & $1.3[0.93-1.75]$ \\
\hline $40-49$ & & $0.85[0.52-1.36]$ & - & $0.68[0.42-1.0]$ \\
\hline \multicolumn{5}{|l|}{ Religion } \\
\hline Orthodox & - & Ref & - & Ref \\
\hline Muslim & - & $0.38[0.26-0.53] * *$ & - & $1.1[0.69-1.75]$ \\
\hline Protestant & - & $0.52[0.34-0.77] * *$ & - & $0.90[0.57-1.4]$ \\
\hline Others & & $0.29[0.12-0.64]^{* *}$ & & $0.48[0.21-1.00]$ \\
\hline \multicolumn{5}{|l|}{ Marital status } \\
\hline Single & - & Ref & - & Ref \\
\hline Married & - & $5.9[2-17.7] * *$ & - & $6[1.98-17.5] * *$ \\
\hline Widowed & - & $8[1.9-33.6]^{* *}$ & - & $8[1.92-32.9] * *$ \\
\hline Divorced & - & $4.5[1.4-14.9] * *$ & - & $4.4[1.32-14] *$ \\
\hline \multicolumn{5}{|l|}{$\begin{array}{l}\text { Educational } \\
\text { status }\end{array}$} \\
\hline No-education & - & Ref & - & Ref \\
\hline primary & - & $1.3[0.96-1.76]$ & - & $1.2[0.90-1.65]$ \\
\hline Secondary & - & $4[1.97-8.5]^{* *}$ & - & $4.2[1.99-8.66] * *$ \\
\hline Higher & & $6[1.68-23.4] * *$ & - & $6[1.62-22] * *$ \\
\hline \multicolumn{5}{|l|}{ Wealth status } \\
\hline Poor & - & Ref & - & Ref \\
\hline Middle & - & $1.4[1.0-1.9] *$ & - & $1.3[0.92-1.79]$ \\
\hline Rich & - & $2[1.47-2.7] * *$ & - & $1.6[1.08-2.3] *$ \\
\hline \multicolumn{5}{|l|}{ Literacy level } \\
\hline Illiterate & - & Ref & - & Ref \\
\hline Literate & - & $1.5[1.02-2.08] *$ & - & $1.4[0.94-1.92]$ \\
\hline \multicolumn{5}{|l|}{ Place of delivery } \\
\hline Home & - & Ref & - & Ref \\
\hline Institution & - & $8[6.85,11.65] * *$ & - & $8[6.25-10.62] * *$ \\
\hline \multicolumn{5}{|l|}{ Birth order } \\
\hline $1^{\text {st }}$ & - & Ref & - & Ref \\
\hline $2-3$ & - & $1.32[0.92-1.89]$ & - & $1.33[0.93-1.90]$ \\
\hline $4-5$ & - & $0.99[0.59-1.67]$ & - & $1.04[0.62-1.74]$ \\
\hline $6+$ & - & $0.72[0.46-1.15]$ & - & $0.87[0.54-1.36]$ \\
\hline \multicolumn{5}{|l|}{ Parity } \\
\hline$\leq 2$ & - & Ref & - & Ref \\
\hline $3-5$ & - & 1 [0.73-1.55] & - & $1.09[0.75-1.59]$ \\
\hline$\geq 6+$ & - & Omitted & - & Omitted \\
\hline
\end{tabular}




\begin{tabular}{|c|c|c|c|c|}
\hline Pregnancy status & - & & - & \\
\hline No & - & Ref & - & Ref \\
\hline Yes & - & $0.69[0.51-0.93] *$ & - & $0.79[0.51-0.95]^{*}$ \\
\hline \multicolumn{5}{|l|}{ Age at first birth } \\
\hline $15-24$ & & Ref & & \\
\hline $25-49$ & & $0.69[0.45-1.06]$ & & $0.73[0.48-1.12]$ \\
\hline \multicolumn{5}{|c|}{ Community- level variables } \\
\hline \multicolumn{5}{|l|}{ Region } \\
\hline & & - & & \\
\hline Tigray & & - & Ref & Ref \\
\hline Afar & & - & $0.11[0.049-0.24] * *$ & $0.17[0.07-0.40]^{* *}$ \\
\hline Amhara & & - & $0.49[0.21-1.10]$ & $0.56[0.27-1.17]$ \\
\hline Oromia & & - & $0.14[0.063-0.30] * *$ & $0.17[0.08-0.38]^{* *}$ \\
\hline Somali & & - & $0.025[0.01-0.06] * *$ & $0.035[0.014-0.08] * *$ \\
\hline Benishangul & & - & $0.35[0.15-0.80] *$ & $0.29[0.13-0.64] * *$ \\
\hline SNNPR & & - & $0.14[0.065-0.30] * *$ & $0.18[0.08-0.38]^{* *}$ \\
\hline Gambella & & - & $0.17[0.074-0.40] * *$ & $0.19[0.08-0.42]^{* *}$ \\
\hline Harari & & - & $0.18[0.074-0.43] * *$ & $0.14[0.057-0.35] * *$ \\
\hline Addis Ababa & & & $0.64[0.17-2.30]$ & $0.47[0.13-1.69]$ \\
\hline Dire dawa & & - & $0.21[0.08-0.51] * *$ & $0.19[0.075-0.47] * *$ \\
\hline \multicolumn{5}{|l|}{ Residence } \\
\hline Rural & & - & Ref & Ref \\
\hline Urban & & - & $0.50[0.29-0.85] *$ & $0.95[0.58-1.54]$ \\
\hline \multicolumn{5}{|l|}{$\begin{array}{l}\text { Community } \\
\text { education }\end{array}$} \\
\hline Low education & & - & Ref & Ref \\
\hline High education & & - & $2.4[1.60-3.52]^{* *}$ & $1.5[1.03-2.14] *$ \\
\hline \multicolumn{5}{|l|}{$\begin{array}{l}\text { Community } \\
\text { poverty }\end{array}$} \\
\hline Low poverty & & - & Ref & Ref \\
\hline High poverty & & - & $2.5[1.61-3.72] * *$ & $1.2[0.77-1.78]$ \\
\hline
\end{tabular}

*Key: Ref: Reference group; p-value 0.05-0.01*: p-value $<0.01 * *$ 